\title{
PERANCANGAN APLIKASI BOSEH BIKE SHARING DI KOTA BANDUNG
}

\author{
Eka Listiana $^{1}$, Hadah Muallimah ${ }^{2}$ \\ Program Studi Desain Komunikasi Visual ${ }^{1,2}$ \\ Sekolah Tinggi Teknologi Bandung ${ }^{1,2}$ \\ eka.listiana64@gmail.com ${ }^{1}$, hadahmuallimah@sttbandung.ac.id ${ }^{2}$
}

\begin{abstract}
Abstrak
Hadirnya sepeda BOSEH Bike sharing di Kota Bandung merupakan langkah yang baik dalam mewujudkan transportasi umum non motor. Tempat registrasi yang hanya tersedia 3 titik di kota Bandung tergolong kurang efisien bagi pengguna, cara peminjaman nya pun tergolong kurang efisien, karena konsol terminal terkadang sulit membaca kartu saat ditempelkan ke konsol terminal. Cara yang kurang efisien ini tentunya berdampak terhadap berkurangnya minat pemgguna dalam menggunakan BOSEH Bike sharing. Oleh karena itu perlu ada nya cara yang lebih efisien untuk proses registrasi, peminjaman dan pengembaliannya. Salah satu solusi yang tepat untuk masalah tersebut adalah pembuatan aplikasi, karena pada zaman sekarang tak bisa dipungkiri masyarakat lebih bergantung pada smartphone yang tentu saja di dalam nya berisi aplikasi, dengan adanya aplikasi ini diharapkan dapat membantu pengguna dalam proses registrasi, peminjaman dan pengembalian dengan efisien.
\end{abstract}

Kata Kunci : Sepeda, Aplikasi, Registrasi, Peminjaman dan Pengembalian

\section{Abstract}

The presence of BOSEH Bike sharing in the city of Bandung is a good step in realizing non-motorized public transportation. Where registration is only available 3 points in the city of Bandung classified as less efficient for users, the way to borrow is also quite inefficient, because terminal consoles are sometimes difficult to read the card when attached to the terminal console. This inefficient method certainly has an impact on the reduced interest of users in using BOSEH Bike sharing. Therefore there needs to be a more efficient way to process registration, lending and repayment. One of the right solutions for this problem is making an application, because in this day and age it cannot be denied that the community is more dependent on smartphones which of course contains applications, with this application it is expected to help users in the process of registration, borrowing and returning efficiently .

Keywords: Bicycles, Applications, Registration, Borrowing and Returning

\section{PENDAHULUAN}

Sepeda merupakan alat transportasi yang ramah lingkungan karena tidak menggunakan mesin bermotor dan bahan bakar. Biasanya sepeda digunakan untuk olahraga, ada juga yang menggunakannya sebagai alat trasnportasi untuk pergi ke suatu tempat, namun saat ini penggunaan sepeda untuk alat transportasi sehari-hari mulai berkurang dan penggunaan nya menjadi bergeser yang semula untuk media transportasi menjadi media olahraga.

Banopolis sebuah konsultan transportasi yang fokus pada non-motorized transportation (transportasi berbasis nonmotor) memiliki ide untuk menjadikan sepeda sebagai transportasi publik yang kerap menjadi pilihan untuk bepergian. Oleh karena Banopolis menyampaikan ide mereka kepada Walikota hingga akhirnya disetujui dan lahirlah BOSEH. Tentu saja kehadiran sepeda BOSEH ini diharapkkan juga mengurangi polusi dan badan menjadi lebih sehat tentunya [1].

Sistem peminjaman Boseh yang canggih ini tentu saja merupakan inovasi yang baik, namun dalam cara registrasi dan peminjamannya terbilang masih kurang efisien. Untuk registrasi kita harus datang ke booth BOSEH yang hanya ada tiga titik booth di kota Bandung, selain itu kita harus membeli kartu Brizzi yang bisa kita dapatkan di Bank BRI atau di booth BOSEH. Untuk cara peminjaman nya juga tergolong kurang efisien karena masih menggunakan konsol terminal yang sering terjadi error. Serta banyak yang masih bingung bangaimana cara peminjaman nya. Dewasa kini aplikasi menjadi media yang banyak digunakan oleh masyarakat, karena dapat mempermudah pekerjaan serta aplikasi dapat menjadi media penyebaran informasi yang efisien dan daya sebarnya luas.

Berdasarkan keterangan tersebut terdapat permasalahan yang timbul bagaimana cara membuat media yang praktis dan efisien untuk peminjaman sepeda BOSEH. maka penulis tertarik untuk mengangkat perancangan dengan judul : "PERANCANGAN APLIKASI BOSEH BIKE SHARING DI KOTA BANDUNG"

\section{LANDASAN TEORI}

1. Perancangan Aplikasi

Perancangan dapat diartikan dengan proses/perbuatan merancang sesuatu [2]. Perancangan dilakukan sebelum mengimplementasikan sesuatu agar mengurangi tangkat kesalahan dalam pengimplementasian sesuatu. Dalam pendapat lain, perancangan adalah sebuah proses untuk mendefinisikan sesuatu yang akan dikerjakan dengan menggunakan teknik yang bervariasi serta didalamnya melibatkan deskripsi mengenai arsitektur serta detail komponen dan juga keterbatasan yang akan dialami dalam proses pengerjaannya[3].

Aplikasi merupakan perangkat lunak yang menggabungkan beberapa fitur tertentu dengan cara yang dapat diakses oleh pengguna[4]. Dapat disimpulkan jika pengertian dari perancangan aplikasi adalah suatu kegiatan/proses merancang sebuah aplikasi untuk memudahkan perancang membuat sesuatu sebelum mengimplementasikan hal tersebut. 


\section{Desain}

Pengertian dari desain adalah kerangka bentuk, rancangan, motif, pola dan corak[5]. Pendapat lain mengatakan bahwa arti dari desain merupakan terjemahan fisik mengenai aspek sosial, ekonomi, dan tata hidup manusia, serta merupakan cerminan budaya zamannya. Desain adalah salah satu manifestasi kebudayaan yang berwujud, desain adalah produk dari nilai-nilai yang berlaku pada kurun waktu tertentu[6].

\section{Bersepeda}

Bersepeda berasal dari kata sepeda yang berarti kendaraan beroda dua atau tiga, mempunyai setang, tempat duduk, dan sepasang pengayuh yang digerakkan kaki untuk menjalankannya[7]. Bersepeda dapat diartikan kegiatan mengendarai sepeda. Kegiatan bersepeda ini dapat dilakukan oleh berbagai kalangan serta usia. Bersepeda juga merupakan suatu hobi yang menyehatkan badan sehingga banyak sekali yang menyukai kegiatan ini.

\section{PEMBAHASAN}

\section{Konsep Umum}

Konsep yang akan menjadi acuan seorang desainer dalam merancang desain - desain nya. Ini merupakan peta jalan seorang desainer untuk menentukan proses desain kita. Konsep umum dalam perancangan ini adalah melalui media informasi berbentuk aplikasi dengan gaya desain flat design. Adapun tujuan perancangan aplikasi ini yaitu untuk memberikan informasi dan mempermudah akses pengguna BOSEH bike sharing, dari mulai peminjaman sepeda dengan, informasi peminjaman, dan informasi seputar sepeda.

2. Kreatif Brief

a. Objective; memberikan informasi seputar BOSEH dan mempermudah cara peminjaman dari metode peminjaman BOSEH sebelumnya, yang diharapkan akan menambah minat dalam penggunaan BOSEH bike sharing.

b. Issue; informasi peminjaman sepeda BOSEH belum tersebar, dalam cara registrasi nya pun masih terbilang cukup rumit karena harus mendatangi booth BOSEH yang hanya ada tiga titik di kota Bandung, belum lagi metode peminjaman nya yang rumit diharuskan memiliki kartu Brizzi. Padahal zaman sekarang mobile apps sudah menjamur dikalangan masyarakat.

c. Opportunity; metode peminjaman BOSEH yang kurang efisien yang mengharuskan pengguna mendaftarkan diri ke booth BOSEH yang hanya ada tiga titik di kota Bandung, dan mengharuskan pengguna memiliki kartu Brizzi. Hal ini lah yang membuat penulis merancang sebuah strategi dalam rangka memberikan akses peminjaman yang lebih mudah untuk pengguna BOSEH.

d. Challenge; tantangan nya adalah bagaimana membuat aplikasi yang menarik agar memudahkan pengguna BOSEH.

\section{Konsep Kreatif}

Konsep kreatif dalam perancangan ini adalah memberikan kemudahan dalam mengakses peminjaman BOSEH dengan menggunakan media digital berupa Aplikasi. Agar perancangan menjadi tepat makan di buatlah konsep kreatif agar sesuai dengan target yang ditentukan.

\section{Konsep Verbal}

Konsep verbal dalam perancangan ini adalah membuat media digital yang memudahkan pengguna BOSEH dalam menggunakan sepeda BOSEH, disampaikan dengan Bahasa yang mudah di mengerti agar target audience memahami dengan mudah.

\section{Konsep Visual}

Konsep visual yang ada dalam perancangan ini adalah bagaimana membuat sebuah ide kedalam bentuk visual yang mudah dibaca dan ditanggapi, sehingga pesan atau ide gagasan yang sudah dibuat sampai kepada target audience.

\section{Konsep Identitas Perancangan}

Dalam sebuah produk, identitas merupakan hal yang penting guna mempromosikan kampanye produk tersebut, dengan identitas produk yang unik akan membuat produk mudah di ingat. Identitas yang digunakan dalam perancangan ini adalah "HAYU NGABOSEH" yang berasal dari kata "HAYU" adalah Bahasa sunda yang artinya "AYO" dalam artian adanya ajakan dan dorongan, dan kata "NGABOSEH" merupakan Bahasa sunda yang artinya "MENGAYUH", dengan kata "NGABOSEH" juga dapat mewakili produk karena menggunakan kata yang sama yaitu "BOSEH". 


\section{Ilustrasi}

Ilustrasi adalah hasil visualisasi dari suatu tulisan dengan teknik drawing, lukisan, fotografi, atau teknik seni rupa lainnya yang lebih menekankan hubungan subjek dengan tulisan yang dimaksud daripada bentuk. Pada perancangan ini ilustrasi yang digunakan adalah menggunakan gaya desain flat design, karena tren desain sekarang lebih mengacu pada flat design, serta pemilihan desain ini diambil dari persentase pengguna yang sebagian besar nya adalah remaja. Flat Design merupakan sebuah gaya design yang dimana teknik dasar penggunaannya di lakukan dengan cara menghilangkan karakter gaya pada suatu objek, seakan- akan gambar tersebut sedang mengambang. Yang dapat diartikan dengan cara menghilangkan karakter gaya pada desain, contohnya seperti gradiasi (gradient) dan tekstur (texture) nya. Dan karakter lain yang pada desain digunakan untuk membuat tampilan desain itu seolah- olah menjadi design tiga dimensi yang rata.

8. Studi Visual Aplikasi

a. Font; pada perancangan aplikasi ini menggunakan font BP replay regular, dan BP replay bold. Font ini dipilih karena memiliki karakter nya yang lebih modern, dan friendly sesuai target audience.

b. Warna; warna utama yang dominan digunakan adalah warna biru dan putih. Tujuan digunakan nya warna ini adalah karena berpacu pada warna logo BOSEH.

c. Ilustrasi; Ilustrasi yang digunakan pada perancangan ini adalah menggunakan ilustrasi flat design. Ilustrasi ini dipakai karena menyesuaikan target audience.

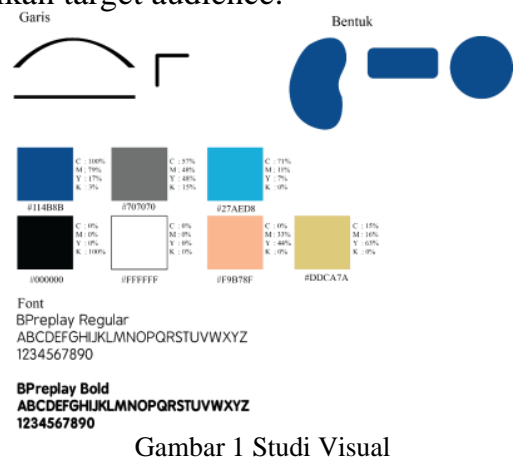

9. Artwork

Mencari ide dan konsep dalam membuat aplikasi tidaklah mudah, dari beberapa media kreatif yang sudah di teliti, media utama dari perancangan ini adalah Aplikasi, karena saat ini orang orang sudah banyak menggunakan smartphone. Dengan media aplikasi BOSEH ini bisa memuat berbagai informasi dengan lengkap, dan tambahan fitur yang lebih canggih tentunya akan memudahkan pengguna baik itu pengguna baru ataupun pengguna lama.

\section{Rapid Prototype}

Prototype adalah simulasi dari hasil akhir sebuah produk. Seperti mockup interaktif yang memiliki tingkat ketelitian yang tinggi. Tujuan utama dalam pembuatan prototype adalah untuk menguji apakah flow dari sebuah produk sudah lancar dan konsisten. Rapid prototype pada UX berfungsi sebagai gambaran dasar bagaimana penataan letak dari berbagai macam element.

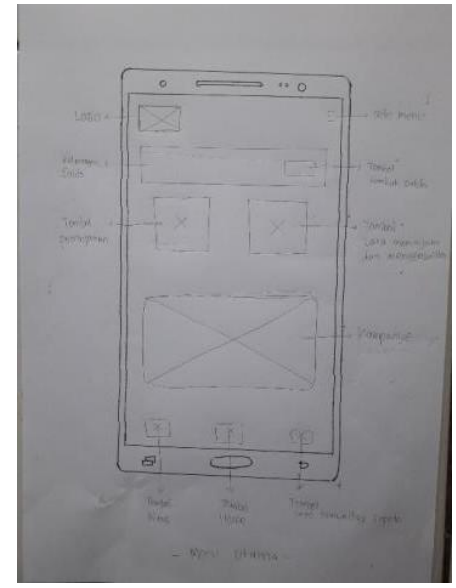

Gambar 2. Rapid Prototype 


\section{Strategi Media}

Media Aplikasi tentunya mudah digunakan efisien dan mudah disebar luaskan karena pada zaman sekarang orang orang sudah menggunakan Aplikasi disetiap aktivitas nya. Dengan Aplikasi BOSEH ini bisa memudahkan pengguna dalam proses registrasi dan proses peminjaman, dan pengembalian.

12. Media Utama

Dalam proses pembuatan UI media utama ini menggunakan Aplikasi Adobe XD cc 2019 dengan ukuran 360 x 640 px

13. Media Pendukung

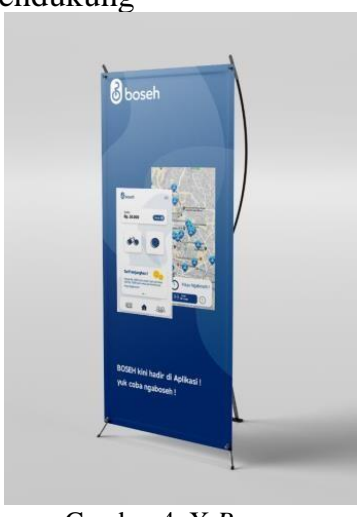

Gambar 4. X Banner

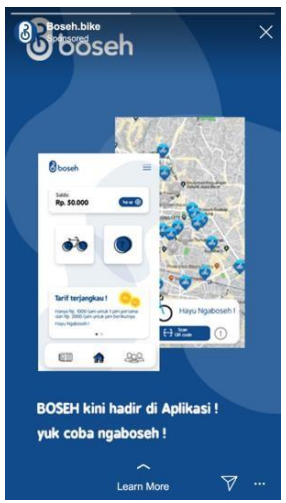

Gambar 6. Instagram Ads

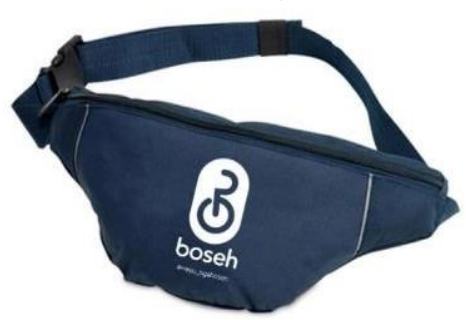

Gambar 8. Waist Bag
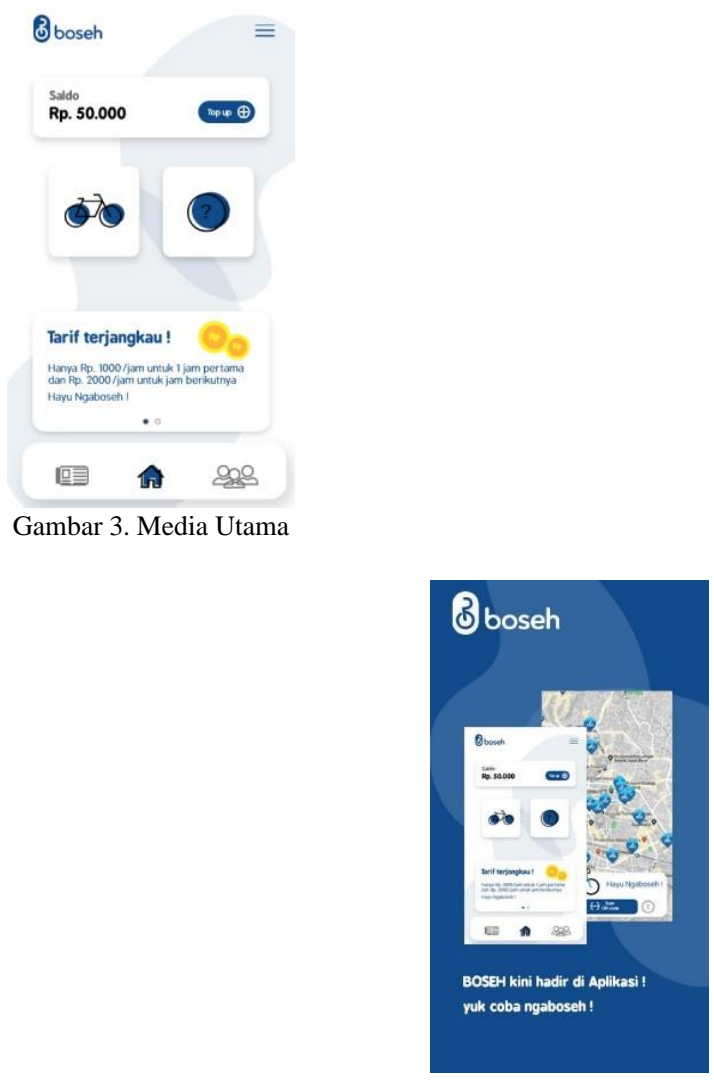

Gambar 5. Poster

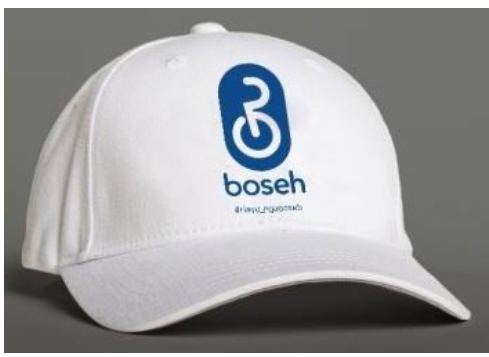

Gambar 7. Topi

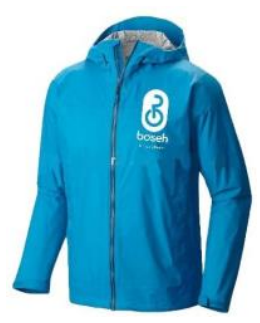

Gambar 9. Jas Hujan 


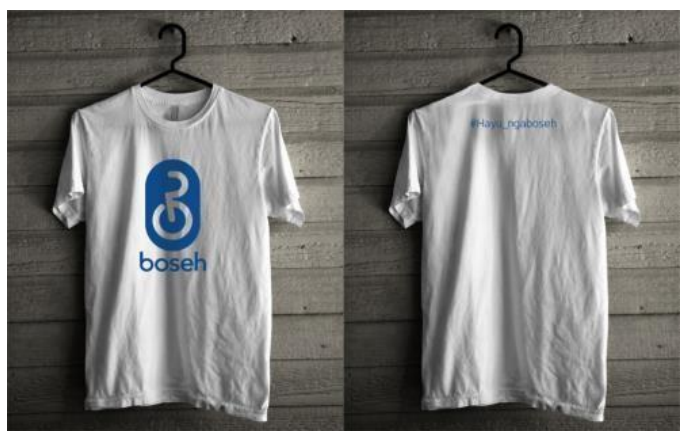

Gambar 10. Kaos

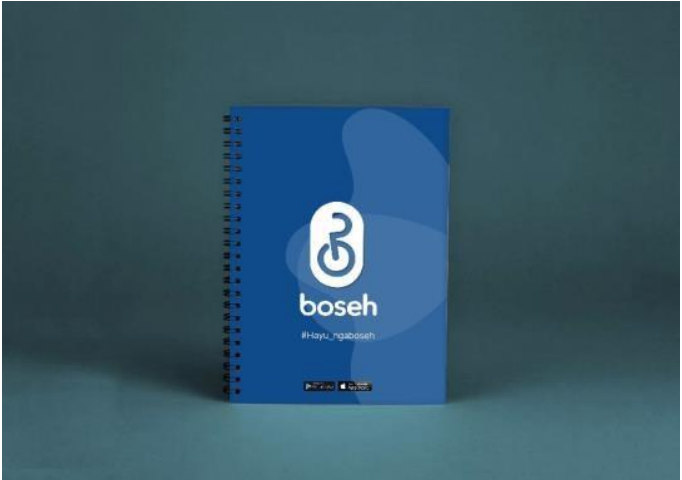

Gambar 12. Notebook

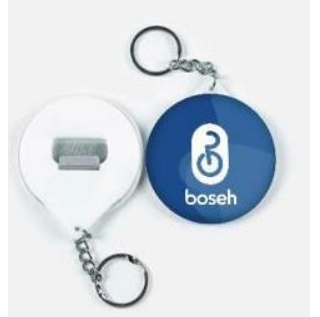

Gambar 14. Gantungan Kunci

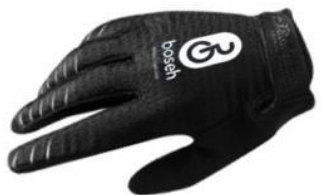

Gambar 16. Sarung Tangan

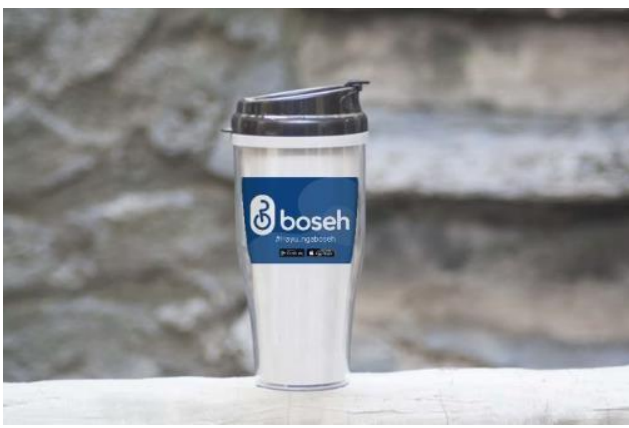

Gambar 11. Tumbler

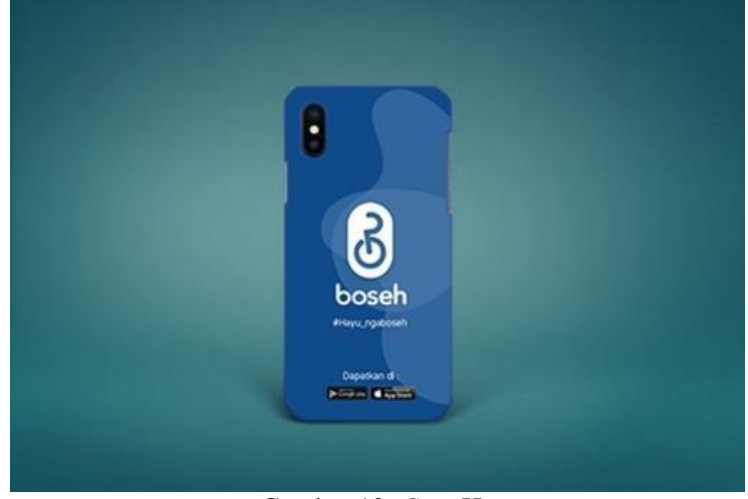

Gambar 13. Case Hp

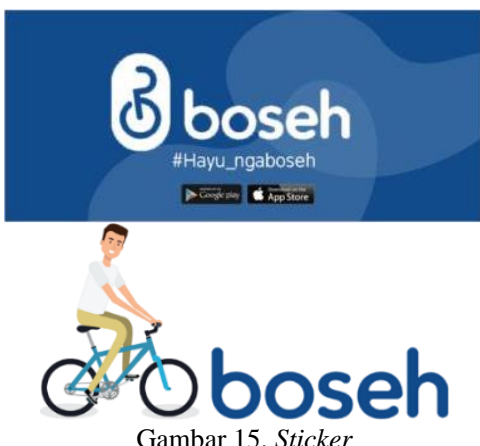

Gambar 15. Sticker

\section{KESIMPULAN}

Dalam penelitian ini dapat ditarik kesimpulan bahwa banyaknya pengguna BOSEH bike sharing yang masih kesulitan dalam hal registrasi, dan banyak yang kebingungan dan lupa saat peminjaman dan pengembalian, maka dari itu dibuatlah aplikasi yang memudahkan pengguna untuk registrasi dan peminjaman nya.

\section{REFERENSI}

[1] https://www.rappler.com/world/bahasa-indonesia/160156-banopolis-bike-sharing-boseh-bandung/. Diakses 16 Maret 2021

[2] https://kbbi.kemdikbud.go.id/entri/perancangan. Diakses 17 Maret 2021

[3] Rizky, Soetam. 2011. Konsep Dasar Rekayasa Perangkat Lunak. Jakarta: PT. Prestasi Pustakaraya

[4] https://idcloudhost.com/pengertian-aplikasi-arti-fungsi-klasifikasi-dan-contoh-aplikasi/\#Mengenal_Pengertian_Aplikasi. Diakses 16 Maret 2021

[5] https://kbbi.kemdikbud.go.id/entri/desain. Diakses 16 Maret 2021

[6] Sachari, A dan Sunarya, Y Y. 2002. Sejarah Dan Perkembangan Desain Dan Dunia Kesenirupaan Di Indonesia. Bandung: Institut Teknologi Bandung.

[7] https://kbbi.kemdikbud.go.id/entri/sepeda. Diakses 17 Maret 2021 